\title{
SHALL, MUST, MAY: THE LOGIC OF LEGAL OBLIGATION AND PERMISSION
}

\section{BEN RUSSELL}

This article seeks to place legal drafting into a structured, logical system. It divides legal sentences into those which confer obligation or permission (called "performatives"), and those which describe obligation or permission (called "deontic declaratives"). It adopts George Coode's views as to the grammatical form of performatives. It then attempts to classify the logical relations between the various types of sentences. The relation holding berween deontic declaratives is the traditional relation of "entailment"; the relation holding between performatives is a new relation the author calls "covering". In the case of performatives that impose obligations ("imperatives"), covering relations mirror entailment relations. The situation is more complicated for performatives that grant permission ("permissives"). The author attempts to analyze permissives in terms of providing defences to claims. He finds that covering relations between permissives do not mirror entailment relations. To this, and to confusions between performatives and declaratives, the author attributes various "paradoxes of permission." The author observes that the results of inconsistent drafting are "quandaries" in which a person is both obliged to perform an act and is prohibited from performing it. Despite current trends toward plain language drafting, the author endorses Coode's view that logical analysis is the key to improving legal drafting.
Le présent article cherche d̀ situer la rédaction juridique dans un système structuré logiquement, où les phrases sont divisées en deux catégories : celles qui imposent une obligation ou accordent une permission (dites «performativesw) et celles qui décrivent une obligation ou permission (dites "déclaratives déontiquesu). II adopte les principes énoncés par George Coode quant à la forme grammaticale des actes de parole performatifs. II tente ensuite de classer les liens logiques entre les différents types de phrases. Le rapport existant entre les déclaratifs déontiques est ce que l'on appelle traditionnellement une *relation de conséquence ou implication logiques; la relation entre performatifs est une relation nouvelle que l'auteur qualifie de "covering». Dans le cas des performatifs qui imposent des obligations (impératifs), les relations de couverture reflètent les relations de conséquence logique. La situation se complique pour les verbes performatifs qui accordent une permission (permissifs). L'auteur tente d'analyser les verbes permissifs en ce qu'ils donnent matière d défense en cas de poursuite. Il trouve que les relations de couverture entre verbes permissifs ne reflètent pas les relations de conséquence. C'est à cette caractéristique et à la confusion existant entre les modalités performatives et déclaratives que l'auteur attribue divers «paradoxes de permission». L'auteur note que le manque de rigueur des rédacteurs provoquent des impasses où une personne est à la fois obligée et empêchée d'effectuer certains actes. Malgré la tendance actuelle à la simplification, l'auteur appuie le point de vue de Coode selon lequel l'analyse logique permet d'améliorer la rédaction juridique.

\section{TABLE OF CONTENTS}

I. INTRODUCTION $\ldots \ldots \ldots \ldots \ldots \ldots \ldots \ldots \ldots \ldots$

II. THE FORM OF LEGAL SENTENCES $\ldots \ldots \ldots \ldots \ldots \ldots \ldots 9$

III. THE MEANING OF LEGAL SENTENCES $\ldots \ldots \ldots \ldots \ldots \ldots 99$

A. IMPERATIVES $\ldots \ldots \ldots \ldots \ldots \ldots \ldots \ldots \ldots \ldots$

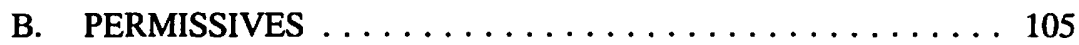

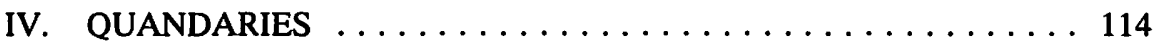

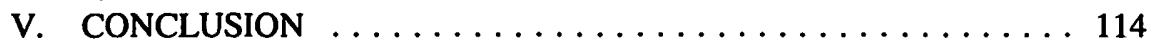

Bishop \& McKenzie. 


\section{INTRODUCTION}

When someone in authority commands someone to do something, we often describe the result in terms of obligation. When a mother tells her child to Clean your room! for example, we are apt to say The child has to clean her room, or She must clean her room. In doing so there is usually a clear distinction between the imperative sentence that imposes the obligation (Clean your room!) and a declarative sentence that describes the result (She must clean her room).

This article is based on the premise that there is a similar distinction to be made in legal language. That is, many sentences found in contracts and statutes function like imperatives. In effect they command someone to do something. Such sentences impose obligations. For example: The Tenant shall pay annual rent of $\$ x$.

Opposed to sentences that impose obligations are sentences that describe existing obligations. They do not have "legal force": they do not create or change the pre-existing legal relations between the parties. They occur, for example, in counsel's submissions to the Court: It is our submission, Milord, that the Tenant must pay annual rent of $\$ x$.

One sign that a sentence is intended to impose an obligation (rather than merely describe it) is the use of the auxiliary verb shall. Here is how E.A. Driedger, Q.C. contrasted Every one shall... with Every one must...:

Strictly speaking,...[Every one must] does not directly create a duty; it merely asserts the existence of a duty, however it may have been created. Thus, anyone can say that all motorists must drive on the right, because the legislature has said that they shall.... Hence, in directing commands to persons shall is better.'

A similar distinction can be made with respect to permission. Some sentences confer or grant permission to do something; other sentences are used to describe the permission so granted. But while the distinction between imposing and describing obligations is mirrored by the two auxiliary verbs shall and must, with respect to permission there is only one auxiliary verb used both to grant and to describe permission: the auxiliary verb may. ${ }^{2}$

In order to keep track of these distinctions I will introduce some terminology. If a sentence has legal effect (if it changes the legal relations between the parties), I will call

1 E.A. Driedger, The Composition of Legislation (Ottawa: Queen's Printer, 1976) at 10. In contracts and statutes "must" is traditionally used to state conditions of validity that do not directly impose a duty on anyone, e.g., Alberta Business Corporations Act, R.S.A. 1981, c. B-15, s. 100(3)):

At least half of the directors of a corporation must be resident Canadians.

If must is used in place of shall to impose obligations (as the Plain Language Movement of drafting now advocates), another locution must be found to perform the traditional role of must.

$2 \quad$ See the Interpretation Act, R.S.A. 1980, c.I-7, s.25(2): In an enactment, ...may shall be construed as permissive and empowering, ...shall is to be construed as imperative. 
it a performative. ${ }^{3}$ Imperatives are performatives used to impose obligations; permissives are performatives used to grant permission.

If a sentence has no legal effect, but is used merely to describe a situation, I will call it a declarative. I will speak of two types of declaratives: factual declaratives like The Tenant paid rent that do not describe obligations and permission, and deontic declaratives like The Tenant must pay rent that do describe legal obligations and permission.

The aim of this article, then, is to chart some of the logical relations among legal performatives and declaratives, taking the approach that deontic declaratives describe the pattern of obligations created by performatives. The article attempts to analyze permissives, and suggests that certain paradoxes of permission (von Wright's Paradox, McLauglin's Paradox) arise from failure to distinguish the use of may in deontic declaratives from its use in permissives. I hope the article also shows how legal drafting can be a fertile source of examples with which to test logical systems, and how logicians' insights can contribute to the understanding and improvement of legal drafting.

\section{THE FORM OF LEGAL SENTENCES}

Legal performatives can take many forms, but there is one widely-used form that I will concentrate on and take as paradigmatic. It was described by the English barrister George Coode in his appendix to a report on taxation presented to the English Parliament in $1843 .{ }^{4}$ Coode's work has since become the classic work on legal drafting.

According to Coode, every legal sentence either confers a right, power or privilege on someone, or imposes an obligation on someone. Therefore every legal sentence has two essential parts, a description of the legal subject (the person on whom the right or obligation is conferred), and a description of the legal action (the right or obligation conferred). In addition, a legal sentence can contain clauses that describe the cases and conditions in which the sentence is intended to operate. Here is how Coode analyzed a typical legal sentence:

Case: When any overseer...has reason to believe that the parish is aggrieved by any county rate...

Condition: $\quad$ if such overseer give 14 clear days' notice...

Legal Subject: such overseer

Legal Action: may appeal against such part of the rate as may affect the parish. 1962). In introducing the concept, Austin uses as examples legal performatives using the word hereby, as in $A$ hereby grants $x$ to $B$.

$4 \quad$ Coode's work is reprinted in Driedger, supra note 1 at 317. 
Since every legal sentence confers a right or obligation, ${ }^{5}$ Coode believed each sentence must contain either may or shall. He wrote:

In English the words may and shall, with their negatives, are exclusively the proper auxiliaries of the enacting verb.... If a right, privilege, or power is conferred, the appropriate copula is may or may not; ... if an obligation is imposed to render any duty, the proper copula is shall; if the obligation is to abstain, the appropriate copula is shall not.... Not one case can be imagined, in which it is necessary or convenient to use any other than permissive or imperative language in the enacting verb; and [the following rule] therefore, ought never to be allowed to be infringed;...that the copula, which joins the legal subject and the legal action, is to be may, or may not, or shall, or shall not...

There are three minor modifications or clarifications that should be made to Coode's analysis. The first involves the use of may not. Coode was right (it is submitted) in stating that shall is used to impose an obligation to do something, and shall not to impose an obligation to refrain from doing something. He was also right in stating that may is used to grant permission to do something. But he was wrong to imply that may not is used to grant permission to refrain from doing something. The sentence ${ }^{7}$

(1) You may not smoke.

does not mean

You are permitted not to smoke. (i.e. You may refrain from smoking).

Rather, (1) means

(3) You are not permitted to smoke.

The second modification to Coode's analysis concerns his distinction between cases and conditions. In practice this distinction is hard to make (arguably, it is a distinction without a difference), so I will use the word condition to include what Coode called cases.

Finally, Coode used in his examples (but did not discuss) compound sentences formed by joining two simpler sentences with and, as in

Company A shall maintain the building and Company B shall keep the parking lot free of snow.

I will call any performative that corresponds to Coode's analysis (including compound performatives joined by and) a Coode sentence. If we replace words and phrases with

I slide over the (admittedly valid) distinction between a grant of permission and a grant of power. Every grant of a power seems to me to include a grant of permission.

Driedger, supra note 1 at 329-330.

When used to signify permission, the not in may not negates the auxiliary verb; when used to signify future possibility, the not in may not negates the main verb. See R. Quirk and S. Greenbaum, $A$ University Grammar of English (Harlow: Longman, 1973) at 189: They may not bother to come if it's wet. 
letters of the alphabet to better display their form, ${ }^{8}$ the following are examples of Coode sentences:

If $p$, A shall not $F$.

An $M$ shall $F$ or $G$.

Every $\mathrm{M}$ or $\mathrm{N}$ shall $\mathrm{F}$.

$A$ and $B$ may $F$, except when $p$.

A remarkably high percentage of sentences actually found in contracts and statutes are Coode sentences, or close cousins to them. Here are some examples, taken from the Alberta Business Corporations Act: ${ }^{9}$

19(1) A corporation shall at all times have a registered office within Alberta.

(3) Subject to subsection (4), the directors of the corporation may at any time

(a) change the address of the registered office within Alberta,

(b) designate, or revoke or change a designation of, a records office within Alberta, or

(c) designate, or revoke or change a designation of, a post office box within Alberta as the address for service by mail of the corporation.

(5) A corporation shall send to the Registrar, within 15 days of any change under subsection (3) or (4), a notice of that change in the prescribed form, and the Registrar shall file it.

(6) The corporation shall ensure that its registered office and its records office are

(a) accessible to the public during normal business hours, and

(b) readily identifiable from the address or other description given in the notice referred to in subsection (2).

Although Coode sentences are common, statutes and contracts also contain many sentences that are not Coode sentences, most of which function perfectly well. But it is instructive to observe how some non-Coode sentences would fail if one tried to use them as performatives.

Consider, for example, the fact that the only conjunction used to form Coode sentences is and. Thus (1) is a Coode sentence, but (2), (3), (4) and (5) are not:

(1) A shall F and B shall G.

(2) A shall F or B shall G.

(3) A may F or B may G.

$8 \quad I$ use $A$ and $B$ to replace proper names of individuals and corporations, $M$ and $N$ to replace common noun phrases, $F$ and $G$ to replace verb phrases, and $p, q$ and $r$ to replace declarative clauses.

$9 \quad$ R.S.A. 1980 , c. B-15 [herinafter ABCA]. 
It is not the case that A shall $\mathrm{F}$.

$$
\text { If A shall } \mathrm{F}, \mathrm{B} \text { shall } \mathrm{G} \text {. }
$$

The problem with sentences (2) to (5) becomes more evident when they are paraphrased as:

(2) I hereby command A to F or I hereby command B to G.

(3) I hereby grant A permission to do F or I hereby grant B permission to do G.

(4) I do not hereby command A to F.

(5) If I hereby command A to F, then I hereby command B to G.

The problem with these sentences is that they do not unequivocally command (or grant permission to) any specific person to do any specific act. If a litigant tried to rely on (2), for example, his or her opponent would resist along these lines: "My friend submits that (2) requires $A$ to do $F$ or $B$ to do $G$. Well which is it? The sentence does not make that clear. Surely it is void for uncertainty." The fact of the matter is that sentences (2) to (5) simply do not form part of the legal dialect. They are not to be found in actual contracts and statutes. ${ }^{10}$

Note too that Coode sentences are always in the active voice, with the subject being the legal person on whom the obligation or permission is conferred. Inactive and passive performatives are in fact quite common, and in most such cases the legal subject on whom the obligation or permission is conferred can be ascertained from the context. Where the legal subject cannot be ascertained, however, the provisions are defective:"1

The auxiliaries shall and may are used outside the legal dialect to express things other than obligation and permission. Shall is used in the first-person in Southern British English to express the future (I shall come on Tuesday), for example, and may is used to express possibility (It may rain). Lawyers sometimes confuse the uses of shall and may and produce barbarisms like:

If the Tenant shall default, the Landlord may re-enter.

The Tenant shall prepay taxes in such amounts as the Landlord may determine.

The preferred alternatives to these are

If the Tenant defaults, the Landlord may re-enter.

The Tenant shall prepay taxes in such amounts as the Landlord determines.

In older drafting styles, shall is sometimes used to state a rule of law, as well as to impose an obligation on an identifiable person, for example

$\begin{array}{ll}\text { Older Form } & \text { Modern Form } \\ \text { shall have a lien } & \text { has a lien } \\ \text { shall be entitled } & \text { is entitled } \\ \text { shall be forfeited } & \text { is forfeited } \\ \text { shall be liable } & \text { is liable }\end{array}$

Driedger, supra note 1 at 13 . Outside the legal context, passive and inactive sentences describing obligations are sometimes used, e.g. There ought to be no pain. This has been analyzed as stating that in an ideal world, there would be no pain. See Hector-Neri Castaneda, "On the Semantics of the Ought-10-do," in D. Davidson \& G. Harman, Semantics of Natural Language (Synthese Library, 1972) at 675 . 
(6) All motor vehicles carrying loose materials shall have such loads securely covered. ${ }^{12}$

(7) Articles of Incorporation shall be in the prescribed form. ${ }^{13}$

(8) [When there is an escape of flammable or combustible liquids,]...all reasonable steps shall be taken to recover escaped liquid and remove contaminated soil.

The problem with these imperatives is exemplified by sentence (8), which is $\mathrm{s.139(2)}$ of Alberta Fire Code Regulation. ${ }^{14}$ It was at the center of litigation concerning a leak of gasoline from an underground storage tank at a gas bar. When the Fire Marshall ordered the landowner, lessee, gas bar operator, and gasoline owner to clean up the leak pursuant to (8), each argued that (8) imposed a duty on one or more of the others, but not on itself.

Sentences (6), (7) and (8) lead to the reason I consider Coode sentences to be paradigmatic. It is essential to our concepts of legal obligation and permission that they be conferred on someone. It is also essential that the person on whom the obligation or permission is conferred be the same person whose act satisfies or exercises them. ${ }^{15}$ In first naming the person on whom the obligation or permission is conferred, and in then describing the act he or she must or may perform, Coode sentences function very much like:

(19) Jessica, clean your room! ${ }^{16}$

\section{THE MEANING OF LEGAL SENTENCES}

\section{A. IMPERATIVES}

The picture that will guide our analysis of legal performatives is this: Before drafting a legal document (say a lease), a legal drafter and his or her client typically review a number of possibilities, e.g.:

(1) The Tenant pays annual rent of $\$ \mathrm{x}$ and maintains the premises.

(2) The Tenant pays annual rent of $\$ x$ and the Landlord maintains the premises.

(3) The Tenant competes with other tenants for business.

(4) The Landlord reimburses the Tenant for installing improvements.

This example is from E.A. Driedger, A Manual of Instructions for Legislative and Legal Writing (Ottawa: Ministry of Supply and Services, 1989) at 553.

13 ABCA, supra note 9 at s. 5.

$14 \quad$ Alta. Reg. 151/84.

15 A person can make himself legally answerable for something that does not involve his own act, for example, when a seller warrants that goods (which he or she has neither manufactured nor inspected) are of merchantable quality. But I would call this a warranty, not an obligation. 
When the lease is ultimately drafted and executed, it contains performatives that determine what possible situations will satisfy it. For example, the situation described by (1) would satisfy the following imperative, but (2) would not:

The Tenant shall pay annual rent of $\$ x$ and maintain the premises.

The relationship between imperatives and the situations that satisfy them was succinctly summarized by Wittgenstein as follows: ${ }^{17}$

If an order runs "do such-and-such" then executing the order is called "doing such-and-such."

That is, a singular imperative like $A$ shall do such-and-such is satisfied just when A performs the act of doing such-and-such, i.e., in just those possible situations in which $A$ does such-and-such is true. ${ }^{18}$ The imperative is breached when A refrains from that act, i.e. when $A$ does such-and-such is false. Generally, a person satisfies an imperative if that person performs the acts it requires and refrains from the acts it prohibits, and a situation satisfies an imperative if everyone in the situation satisfies the imperative.

In the case of general imperatives, legal drafters commonly use the form

An $M$ shall $F$

to impose obligations on each member of the class of M's, as in

A corporation shall at all times have a registered office in Alberta.

A corporation satisfies this imperative if it has a registered office in Alberta, of course, and a possible situation satisfies it if the following declarative is true in it:

Every corporation has a registered office in Alberta.

Similarly, to impose general prohibitions legal drafters commonly use the following forms interchangeably:

An $M$ shall not $F$

No $M$ shall $F$

as in

17 L. Wittgenstein, Philosophical Investigations, trans. G.E.M. Anscombe (Oxford: Basil Blackwell Publishers, 1968) at para. 458.

is The imperative $A$ and $B$ shall $F$ is distinguished from $A$ and $B$ shall each $F(\Leftrightarrow A$ shall $F$ and $B$ shall $F$ ). The former imposes a single obligation on $A$ and $B$ jointly, and is satisfied if $A$ does $F$ or $B$ does $F$. The latter imposes obligations severally, one obligation on each of $A$ and $B$, and is satisfied only if A does F and B does F. See G. Williams, Joint Obligations (London: Butterworth, 1949). A joint right must similarly be distinguished from several rights. 
No corporation shall have a name that is prohibited by the regulations

or

A corporation shall not have a name prohibited by the regulations.

A corporation satisfies these imperatives if it does not have a prohibited name, and a situation satisfies them if no corporation in that situation has a prohibited name.

So much for the relationship between imperatives and factual declaratives. As for the relationship between imperatives and deontic declaratives, it is succinctly summarized by Driedger in the passage above:

...Anyone can say that all motorists must drive on the right because the legislature has said that they shall.

That is, if in a given situation there is a prevailing imperative covering $A$ shall $F$, then the deontic declarative $A$ must $F$ is true.

In English a factual declarative like $A$ does $F$ can be transformed into the imperative $A$ shall $F$ or into the deontic declarative $A$ must $F$ by the insertion of the respective modal auxiliary, with a minimum of additional syntactic clean-up. We can thus consider legal imperatives and deontic declaratives to be the results of different grammatical operations on factual declaratives. It is therefore convenient to introduce the notation ! $p$ to designate the imperative formed from the factual declarative $p$, and $O p$ to designate the deontic declarative formed from $p$. Using this notation, Wittgenstein's observation is expressed by saying that the imperative ! $p$ is satisfied in those situations where $p$ is true and is breached in those situations where $p$ is false; Driedger's observation is expressed by saying that the imperative ! $p$ (when duly promulgated and when not subject to some incompatible provision) results in the fact that $O p$ is true.

\section{Covering}

The aim of this article is to chart some of the logical relations among legal performatives and declaratives. The main logical relation usually studied, entailment, is generally defined in terms of truth in a possible situation:

Entailment: Declarative $p$ entails declarative $q$ (graphically, $p \rightarrow q$ ) if every possible situation in which $p$ is true is also a possible situation in which $q$ is true. (E.g.: The Tenant pays rent and maintains the premises $\rightarrow$ The Tenant pays rent)

Since legal performatives are neither true nor false, it is necessary to introduce a more general logical relation, which I will call covering. ${ }^{19}$ The basic idea is that sentences are 1966); the spirit from B. van Fraassen, Laws and Symmetry (New York: Clarendon, 1989) at 155. 
used to perform various tasks, and that one sentence covers another if the first performs the task of the second, and therefore renders the second redundant.

Whether one sentence covers another depends on the type of task under consideration. The main task of legal imperatives (I assume) is to make people behave in certain ways by imposing legal obligations (and legal sanctions) on them. I will therefore say that one imperative covers another if the first is at least as strict as the second, i.e.:

Covering: Imperative !p covers imperative $! q$ if $! p$ requires a person to do an act whenever $q q$ requires him to do it.

To draw the parallel with the definition of entailment:

Covering: Imperative ! $p$ covers imperative $! q$ (graphically $p \Rightarrow ! q$ ) if every possible situation satisfying ! $p$ also satisfies !q. (E.g.: The Tenant shall pay rent and maintain the premises $\Rightarrow$ The Tenant shall pay rent).

This notion of covering corresponds to common usage, as in "You don't have to add that clause to the lease, because it has already been covered in paragraph 7."

Another commonly studied logical relation is inconsistency: if two declaratives cannot both be true in the same possible situation, they are said to be inconsistent. Analogously, if two imperatives cannot both be satisfied in the same possible situation, I will say that they are incompatible. (Another word used to describe incompatible imperatives is repugnant, as in "This section is repugnant to that one.")

Sometimes incompatibility is apparent on the face of two imperatives. Other times, however, the incompatibility is relative to given factual constraints: given those facts, the two imperatives cannot both be satisfied. For example, on their face the following are compatible, though they could be incompatible if B's land were within $\mathbf{3 0}$ meters of the survey marker:

(1) A shall not enter B's land.

(2) A shall strip all the topsoil within a 30 meter radius of the survey marker.

Covering relations among imperatives run parallel to entailment relations among the corresponding factual declaratives: $! p \Rightarrow ! q$ is true exactly when $p \rightarrow q$. These parallels between the relation of covering among imperatives and the relation of entailment among declaratives have sometimes led logicians to identify the former with the latter. To do so (it is submitted) is a mistake. Consider, for example, this passage written by Alf Ross:

[F]rom Slip the letter into the letter-box! we may infer, Slip the letter into the letter-box or burn it! It will be seen that, interpreted as a satisfaction-function, this inference is unimpeachable: if the first imperative is satisfied, (if the letter has been slipped into the letter-box), then the other imperative too has been 
satisfied (it is then true that either the letter has been slipped into the letter-box, or it has been burnt). But it is equally obvious that this inference is not immediately conceived to be logically valid. ${ }^{20}$

The impugned "inference" from Mail the letter! to Mail the letter or burn it! has come to be known as Ross's Paradox. Everyone has his or her own theory about where the difficulty lies. My theory is that Ross was misled by the identification of covering and entailment. For Ross speaks of an "inference". Now, when one is dealing with declaratives, one can "infer" from one declarative to another declarative entailed by it, that is, one can pass in thought from the former to the latter, and can use the latter in one's reasoning in lieu of the former. Thus one can infer from $A$ mailed the letter to $A$ mailed or burnt it. The inference does seem pointless, but only because one passes in thought from a more informative sentence to a less informative one.

But what can one "infer" from an imperative? It is true that $A$ shall mail the letter covers $A$ shall mail the letter or burn it, and not vice versa. That means the former is more strict than the latter, that the former performs the task of the latter (and then some). But it does not mean that one can pass in thought from the former to the latter, and then use the latter in one's reasoning in lieu of the former. Otherwise one would reason that A shall mail the letter could be satisfied by A's burning the letter, which, as Ross says, is not immediately conceived to be logically valid.

So too with the inference from You must mail the letter to You must mail or burn it. As long as both sentences are being used as declaratives, the inference is valid (though admittedly it seems pointless). Sometimes however must is used instead of shall, to impose obligations instead of describing them. In such cases You must mail the letter is used as a performative, and no "inference" is possible to You must mail the letter or burn it.

\section{Conditional Performatives}

As Coode observed, some performatives are conditional. The conditions generally fall into one of two classes. Those of the first class are introduced by words like if, when, whenever, where or wherever. They are, in legal terminology, conditions precedent to the operation of the performative: the performative has no effect unless the condition is fulfilled. Conditions of the second class are introduced by words like unless and except when. They are conditions subsequent to the operation of the performative: the performative has effect just when the condition is not fulfilled.

Using the notation $! p / q$ to designate an imperative $p$ that takes effect just when the condition $q$ is fulfilled, if $q \rightarrow r$ then $! p / r \Rightarrow ! p / q$. For example, the imperative

\section{If}

(a) a corporation acquires a name that contravenes the regulations, or

(b) the Registrar disapproves of a corporation's name, 
the corporation shall change its name.

\section{covers:}

If the Registrar disapproves of a corporation's name the corporation shall change its name.

A conditional imperative has, in those situations where the condition obtains, exactly the same effect as an unconditional imperative, i.e., the imperative ! $\mathrm{p} / \mathrm{q}$ results in the fact that in situations where $q$ is true, $O p$ is true as well. I will use the notation $O p / q$ to describe the result of the imperative ! $p / q{ }^{21}$

Because conditional obligation is involved in various deontic paradoxes, logicians have studied it in some depth. The initial studies assumed (analogously with our treatment of performatives) that if $\mathrm{q} \rightarrow \mathrm{r}$ then $\mathrm{Op} / \mathrm{r} \rightarrow \mathrm{Op} / \mathrm{q}$. Later treatments have been based on the weaker assumption that if $q \leftrightarrow r$ then $O p / r \leftrightarrow O p / q$. The assumption was weakened in part because moral obligations can change with changing circumstances. ${ }^{22}$ For example, there may be a general moral obligation to tell the truth, but this moral obligation is hedged with unstated qualifications and exceptions, so that when unforeseen circumstances arise (when a suicidal person asks where his or her gun is) one's duty is to lie.

In the realm of legal obligations, the problem of conditional obligation is simpler. For although it may be difficult to state the exceptions to which a general principle is subject, it is a difficulty regularly addressed by legal drafters. It may be difficult, for example, to state the circumstances in which one must tell the truth, but a lawyer drafting a prohibition against perjury will nevertheless attempt to state not merely the general principle, but all relevant qualifications and exceptions. Therefore, when an imperative prevails notwithstanding any exceptions, the subject is legally obligated to obey it.

\section{Prevailing Performatives}

Somewhat like conditional performatives are performatives that are subject to other performatives. Sections 79(1) and 79(5) of Alberta's Securities Act, ${ }^{23}$ for example, read as follows:

79(1) Subject to subsection (5), voting securities of an issuer registered in the name of...a registrant...that are not beneficially owned by the registrant...shall not be voted by the registrant....

(5) A registrant...shall vote...any voting securities referred to in subsection (1) in accordance with any written voting instructions received from the beneficial owner.

Section 79(1) says that a registered owner shall not vote securities that he or she does not beneficially own; section 79(5) says that in certain circumstances he or she shall vote them. In the specified circumstances, therefore, the two sections are incompatible. 
The incompatibility is resolved by stating that section 79(1) is subject to 79(5), i.e., in the case of disagreement between sections 79(1) and 79(5), section 79(5) prevails. (The same result could have been achieved by adding the words Notwithstanding subsection (1) to the beginning of 79(5).) Note that the concept of prevailing is distinct from the concept of being in force: Both 79(1) and 79(5) have been duly promulgated and so both are in force, though sometimes $79(5)$ prevails.

The fact that one imperative is subject to another may be implied by law, rather than being expressly stated. In a federal system of government, for example, the federal government and a state government may both validly pass statutes governing a given situation. In Canada, neither statute repeals the other: to the extent possible, one's obligations are determined by both. But if in a given situation the statutes are incompatible, then the federal statute "prevails to the extent of the inconsistency."

\section{B. PERMISSIVES}

We turn now to consider permission, and some of its puzzles.

According to the received view, there are two kinds of permission, Weak Permission and Strong Permission. An act is supposed to be Weakly Permitted if it is not prohibited. Thus we are Weakly Permitted to part our hair on the right, because there are no legally binding imperatives that prohibit us from doing so. An act is supposed to be Strongly Permitted when permission to do the act has been expressly conferred.

This article will deviate slightly from the received view. I suggest that there are not two kinds of Permission. Rather, there are permissives, which grant permission to do an act. And there are deontic declaratives, which describe what one is permitted to do. The distinction is analogous to the distinction between the imperative

\section{(1) A shall $\mathrm{F}$}

and the deontic declarative

(2) A must $\mathrm{F}$

But whereas obligation employs the two words shall and must mirroring the distinction between imperatives and deontic declaratives, permission uses the single word may in both cases. That is,

A may $F$

can be used either as a permissive or as a deontic declarative. I will designate the permissive corresponding to the factual declarative $\mathrm{p}$ as $\mathrm{pp}$, and the deontic declarative as Pp.

I assume that the use of deontic declaratives corresponds to the notion of Weak Permission: the deontic declarative $A$ may $F$ is true in any situation in which no 
imperative would be breached if $\mathrm{A}$ were to $\mathrm{F}$. (That is, $\mathrm{p}$ is permitted if it is not prohibited, so $A$ may $F \leftrightarrow A$ need not refrain from $F \leftrightarrow$ It is not the case that $A$ must not $F$. In symbols, $\mathrm{Pp} \leftrightarrow \sim 0 \sim$ p.)

But how do lawyers use $A$ may $F$ as a permissive? We do not use a permissive to create an especially strong kind of permission. Rather, as a number of authorities have observed, we use permissives to "de-prohibit" acts that would otherwise be forbidden. Here is how Driedger expresses it:

[May] is a grant of permission.... However, it is not complete in itself for it assumes there is a lack of permission.... Thus, if one provision prohibits a course of conduct, then an exception can be made by granting permission with may;....and there might be a provision that an inspector may enter premises and seize goods or do some other act that would otherwise be unlawful. ${ }^{24}$

A typical example of a permissive creating an exception to a prohibition is found in Rules 5.2 and 5.3 of the Alberta Rules of Court: ${ }^{25}$

5.2 Subject to this Part, a person shall only be represented before the Court by a Solicitor.

5.3 An individual may represent himself before the Court.

Rule 5.2 says that all persons (essentially, all individuals and corporations) must be represented by solicitors. The permissive in Rule 5.3, however, sets out an exception for individuals that is incompatible with the general rule, and prevails over it. That is characteristic of permissives: their purpose is to prevail over incompatible imperatives, i.e., to provide a grantee who has done the authorized act with a defence to a claim that the imperative has thereby been breached. ${ }^{26}$

\section{Claims and Defences}

The purpose of a permissive (it is suggested) is to provide its grantee with a defence to a claim. But what is a claim, and what is a defence?

A claim in this context seems to be an allegation that some imperative has been breached. For example, if some person A breached Rule 5.2 of the Alberta Rules of Court, the claim against him or her might take the following form:

C1. Rule 5.2 provides that a person shall be represented before the Court by a solicitor. [!p]

C2. A is a person who is represented before the Court by someone who is not a solicitor. [q]

Supra note 1 at 10.

Alta. Reg. 390/68.

Even in contracts and statutes, the sentence $A$ may $F$ is not always used as a permissive. For stylistic reasons, for example, a drafter may begin by declaring the existing law to the effect that $A$ may $F$, and then derogate from it in a series of imperatives. Or the declarative $A$ may $F$ may be added "out of an abundance of caution", when there is no prevailing prohibition against doing $F$. 
The inference implied in the claim is that the facts alleged in $\mathrm{C} 2$ breach the imperative cited in $\mathrm{C} 1$, i.e., that $\mathrm{q} \rightarrow$ not--p.

Now, according to legal tradition, a defence to a claim takes one of three forms:

Traverse: The defendant denies one or more of the factual allegations against him or her, e.g., A could deny that $q$.

Demurrer: The defendant takes the position that even if the facts alleged were true, they would not support an inference against him or her, c.g. A could deny that there was an imperative in force covering $! p$, or could deny that $q \rightarrow$ not--p.

Confession and Avoidance: The defendant concedes that the allegations in the claim are true and that ordinarily they would support an inference against him or her, but sets out additional facts to show that, in the circumstances, the inference should not be drawn.

What a permissive gives is a defence of confession and avoidance to a claim that could otherwise be made. If Rule 5.3 provided $A$ with a defence to the above claim, for example, A's defence would take the following form:

D1. A admits paragraphs $\mathrm{C} 1$ and $\mathrm{C} 2$ of the claim.

D2. Rule 5.3 provides that, notwithstanding Rule 5.2, an individual may represent himself before the Court. [ $\pi$ ].

D3. A is an individual representing himself before the Court. [s]

The inference implied in A's defence is that the admitted facts (q \& s) "come under the umbrella" of the permissive $\nabla$, i.e. that $(q \& s) \rightarrow r$. The key to the defence, of course, is the assertion that the imperative ! $p$ is subject to the permissive $\sigma$, i.e., that the permissive $\nabla r$ is incompatible with the imperative ! $p$, and prevails over it. It appears that a permissive is incompatible with an imperative when it (expressly or impliedly) authorizes or grants permission to do an act that the imperative (expressly or impliedly) prohibits. ${ }^{27}$

These considerations suggest a definition for covering among permissives:

Covering: $\quad$ Permissive $\nabla p$ covers permissive $\nabla q$ (graphically, $\nabla p \Rightarrow \nabla q$ ) if $\nabla p$ provides a person with a defence whenever $\nabla q$ does.

That is: 
Covering: Permissive $\mathrm{pp}$ covers permissive $\mathrm{vq}$ if $\mathrm{vp}$ authorizes a person to do an act whenever $\mathrm{\nabla q}$ authorizes that person to do it.

\section{Von Wright's Paradox}

The failure to distinguish between the permissive $A$ may $F$ and the deontic declarative $A$ may $F$ can lead to puzzling results. For example, von Wright observed that:

If someone is told he may work or relax this would normally be understood to mean he is permitted to work but also permitted to relax. ${ }^{28}$

That is, $A$ may $F$ or $G$ is in some sense equivalent to $A$ may $F$ and $A$ may $G$. This is clearly so in the legal context. For example, section 19(3) of the ABCA (see above) states in effect:

The directors may

(a) change the registered office,

(b) change the records office, or

(c) change the address for service.

There can be absolutely no doubt that section 19(3) authorizes a change of the registered office and authorizes a change of the records office and authorizes a change of the address for service. The statutes and case law provide thousands of similar examples.

What has puzzled logicians is that $A$ may $F$ or $G$ cannot entail $A$ may $F$ and $A$ may $G$, for otherwise the following argument would be valid:

1. A may $\mathrm{F}$.

2. Therefore, A may $\mathrm{F}$ or $\mathrm{G}$.

3. Therefore, A may $F$ and A may G.

4. Therefore, A may G.

This argument would allow one to infer, from the fact that $A$ is permitted to do some act (F), to the conclusion that $A$ is permitted to do any other act whatsoever (G).

The solution to the puzzle (it is submitted) is simply to distinguish the use of may in permissives from its use in deontic declaratives. Although $A$ may $F$ or $G$ does not entail 
$A$ may $F$ and $A$ may $G$, it does cover it, according to the notion of covering among permissives described above.

Consider, for example, the following variant of Ross's sentence:

(1) A may mail the letter or burn it.

Sentence (1) may be viewed either as a deontic declarative or as a permissive. To view it as a deontic declarative, imagine you are solicitor for the executor of a will. The will contains instructions about some letters found among the testator's personal effects: the executor is authorized to destroy some letters, to mail others back to those who originally sent them to the testator, and to donate still others to the Provincial Archives. A question arises about what is to be done with a particular letter. You are sure that it is not one of the letters to be donated to the Provincial Archives, but you cannot specifically remember what is to be done with it. So you say

A may mail the letter or burn it (I can't remember which).

Sentence (2) is a deontic declarative, and is equivalent to the deontic declarative

(3) A may mail the letter or A may bum the letter.

If the executor is in fact permitted to mail the letter back to its sender, sentence (2) is true. That is, the following entailment relation holds:

$$
\begin{aligned}
& \text { A may mail the letter } \rightarrow \\
& \text { A may mail the letter or burn it }
\end{aligned}
$$

To view (1) as a permissive, imagine you are taking instructions from a testator as to the contents of his will. The question arises about what the testator wants done with a particular letter. The testator says

$$
\begin{aligned}
& \text { A may mail the letter or burn it } \\
& \text { (I don't care which). }
\end{aligned}
$$

Sentence (5) in this context is neither true nor false. It is a permissive which, when incorporated into the will, would provide A with a defence if he or she mailed the letter, i.e.:

$$
\text { A may mail the letter or burn it } \Rightarrow
$$

A may mail the letter

Sentence (5) in this context is not equivalent to (3), for, as we saw in the discussion of Coode sentences, sentence (3) cannot be used as a permissive. 
3. McLaughlin's Paradox

R.N. McLaughlin ${ }^{29}$ questioned whether

(1) A may walk in a public place

follows from

(2) A may walk in a public place wearing clothes.

McLaughlin was accused of committing a logical blunder, for clearly any situation in which (3) is true is also a situation in which (4) is true:

(3) A walks in a public place wearing clothes

(4) A walks in a public place.

Accordingly, any possible situation in which (3) is true and no imperative has been breached, is also a situation in which (4) is true and no imperative has been breached. So (2) evidently entails (1).

Still, it is submitted, McLaughlin's intuitions were sound. To make McLaughlin's example more plausible, consider (5) and (6) instead of (1) and (2):

(5) A may operate a motor vehicle in daylight

(6) A may operate a motor vehicle in daylight while wearing corrective lenses.

Suppose there were an imperative prohibiting people from operating motor vehicles without valid permits, and that $\mathrm{A}$ had been charged with breaching that imperative by driving in daylight without wearing corrective lenses. If the imperative were subject to a permit containing (5), A would on these facts have a defence; if it were subject to (6), A would not have a defence. So (5) provides a defence in some situations where (6) does not. Thus, although (6) entails (5), (6) does not cover (5). That, it is submitted, is the likely source of McLaughlin's misgivings.

\section{The Law of Property Act, s. 49}

The permissive $A$ may $F$ or $G$ (as von Wright observed) authorizes $A$ to do $F$ and also authorizes $A$ to do $G$. But it does not necessarily authorize $A$ to do both $F$ and $G$ in the same situation.

The seize-or-sue provisions of Alberta's Law of Property Act, for example, in specified circumstances permit a secured party to seize collateral or sue for its price; however, the 
provisions prohibit a secured party from seizing and suing in respect of the same collateral. That is, (using hyphens to designate acts done "at the same time") the imperative

A shall not seize and sue

is compatible with

(1) A may seize and A may sue

but is not compatible with

(2) A may seize-and-sue.

(The hyphens are necessary, because $A$ may seize and sue is ambiguous between (1) and (2).)

To grant permission unequivocally to $d o F$, to $d o G$ and to $d o F$-and-G, legal draftsmen must use the formulations like:

A may do either or both of the following:

(a) F;

(b) G.

\section{Covering Relations Among Permissives}

Covering relations among permissives do not run parallel to entailment relations among the corresponding declaratives. In attempting to rationalize them one must consider both the situations in which a permissive provides a defence and the acts for which it provides a defence.

Regarding the situations in which a permissive provides a defence, it appears that $\mathrm{pp}$ provides a defence in all situations where $p$ is true. However, the mere fact that one is exercising a permissive in a situation does not give one immunity against all claims that can be made in the situation. One may have a defence for doing the authorized act, but not necessarily for everything else one does. Here is how Salmond \& Heuston describe the range of immunity granted by permissives: ${ }^{30}$

When a statute authorizes a certain act to be done by a certain person, which would otherwise be unlawful and actionable, no action will lie at the suit of any person for the doing of that act.... The statutory authority and indemnity extends not merely to the act itself but also to all its necessary consequences. When the legislature has authorized an act, it must be deemed also to have authorized by 
implication all inevitable results of that act.... "[T]he criterion of inevitability is not what is theoretically possible but what is possible according to the state of scientific knowledge at the time, having also in view a certain common-sense appreciation which cannot be rigidly defined, of practical feasibility in view of situation and expense." (Manchester Corporation v. Farnworth, [1930] A.C. 171, 183 per Lord Dunedin). But once it is established that the interference exceeded that which would inevitably have resulted from the works authorized the statutory immunity is lost.... [W] here avoidable interference has been caused this will often be due to negligence, which the statute will be deemed not to have authorized and for which liability will be imposed.

The permissive $A$ may $F$ therefore means that if $A$ does $F$ he or she will have a defence for doing $F$ (and for doing $G$, if $A$ does $F \rightarrow A$ does $G$ ); but he or she will not necessarily have a defence to claims brought on other grounds.

Covering relations among permissives flow from the following facts:

(a) A may $F$

provides a defence for doing $F$ in all situations where $A$ does $F$ is true

(b) A may $F$ or $G$

provides a defence for doing $F$ in all situations where $A$ does $F$ is true, and for doing $G$ in all situations where $A$ does $G$ is true

(c) A may $F$-and- $G$ provides a defence for doing $F$-and- $G$ in all situations where $A$ does $F$ and $G$ is true

Thus $A$ may $F$ does not cover $A$ may $F$-and- $G$ because, though the former provides $A$ with a defence in situations where $\mathrm{A}$ does both $\mathrm{F}$ and $\mathrm{G}$, the defence is only for doing $F$ and not for doing $G$. On the other hand, $A$ may $F$-and- $G$ does not cover $A$ may $F$, because, though the former provides a defence for doing $F$, it only provides it in situations where $A$ does $F$ and $G$.

Taking both acts and situations into account, permissive $\mathrm{pp}$ will generally cover permissive $\nabla q$ only when $\mathrm{p} \leftrightarrow \mathrm{q}$. Against this general backdrop, von Wright's observation that $A$ may $F$ or $G$ covers $A$ may $F$ appears as an anomaly. There can be no doubt, however, that von Wright's observation is correct.

\section{Conditional Permissives v. Conditional Permission}

In analyzing conditionals, the distinction must be made between may used in an conditional declarative and may used in a conditional permissive.

The rule for conditional permissives is like that for conditional imperatives: if $q \rightarrow r$ then $\mathrm{pp} / \mathrm{r} \Rightarrow \nabla \mathrm{p} / \mathrm{q}$. In particular, 
For example,

A may sell securities if he files an offering memorandum

covers

A may sell securities if he files an offering memorandum and whistles Dixie

On the other hand, the appropriate definition for the truth of conditional declaratives appears to be:

$\mathrm{Pp} / \mathrm{q}$ is true if there is some possible situation in which $\mathrm{q}$ is true and $\mathrm{p}$ is not prohibited

It follows from this definition that if $q \rightarrow r$ then $P p / q \rightarrow P p / r$, and in particular that

A may $F$ if $q$ and $r \rightarrow A$ may $F$ if $q$

It does not follow that

A may $F$ if $q \rightarrow A$ may $F$ if $q$ and $r$

By virtue of the seize or sue provisions of s. 49 of Alberta's Law of Property Act, for example, this declarative is true:

If the debtor defaults in paying the purchase price, the secured party may seize the collateral.

but the following declarative is false:

If the debtor defaults in paying the purchase price and the secured party sues, then the secured party may seize the collateral.

The interrelationships and contrasts between conditional permissives and conditional permission make for some odd-looking inferences. M. Geiss and A. Zwicky observed, for example, that ${ }^{31}$

(1) If you give me a bite of your ice cream, you may have a bite of mine

seems to invite the inference to

(2) If and only if you give me a bite of your ice cream, may you have a bite of mine.

The inference is explained if we assume (1) is a permissive offered in the context of, but prevailing over, a common law prohibition against trespass to another's goods. Sentence 
(2) is then a declarative describing the resulting circumstances in which you are entitled to a bite of my ice cream.

\section{QUANDARIES}

When a person is the subject of two incompatible imperatives, nothing he or she can do will satisfy them both: he or she is in a quandary. ${ }^{32}$ Observing one quandary, Martland J. in Smith v. The Queen ${ }^{33}$ said "compliance with one law involves breach of the other." Dickson J. (as he then was) in Multiple Access v. McCutcheon ${ }^{34}$ described the phenomenon in these terms: "...There is actual conflict in operation...one enactment says 'yes' and the other says 'no'; compliance with one is defiance of the other."

The law has formulated various rules to resolve quandaries (e.g. the rule that Federal statutes prevail over provincial statutes, that the later statute prevails over the earlier, and that the specific prevails over the general). However, these rules do not extricate clients who, for example, have agreed to sell a given piece of land to two different purchasers. The law will hold such clients to both of their incompatible obligations, the only question being which purchaser will be awarded the land and which will be awarded damages in lieu thereof. ${ }^{35}$

Because a subject in a quandary both is obligated to perform an act and is prohibited from performing it, one widely-accepted axiom of deontic logic fails for legal systems: Op does not entail Pp (must does not entail may). ${ }^{36}$

There is an analogous principle that arguably does apply to legal systems, however: !p covers op (shall covers may, in the permissive sense of covering). One would expect, for example, that if a contract contained an imperative requiring one party to excavate another's land, a court would conclude that the first was also granted permission to excavate the land. If this principle is indeed valid, it appears to have gone without saying, for I have found no judicial authority in support of it.

\section{CONCLUSION}

In Coode's time, as in our own, the quality of legal drafting was widely and justly decried. Today, many reformers urge drafters to follow prescriptive rules derived from declarative prose and purportedly reflecting the plain-speaking idioms of the layperson.

See C.L. Hamblin, Imperatives.

[1960] S.C.R. 776 at 800.

[1982] 2 S.C.R. 161.

An imperative can also clash with a permissive when it prohibits an act that the permissive authorizes. The subject can, if he or she wishes, avoid litigation by refraining from the act, but if he or she does not, the Court is faced with a predicament resembling a quandary. See E. Colvin, "Legal Theory and the Paramountcy Rule" (1979) 25 McGill L.J. 82.

See B. van Fraassen, supra note 21 at 5 . One could save this axiom by assuming that the standard systems of logic describe a system of obligations after all quandaries have been resolved. 
Coode had a different approach. He recommended that legal semantics be analyzed with a view to developing "natural" rules of composition:

None but natural rules, that is to say, such rules as are strictly derived from the nature of the subject matter, and therefore of universal application to it, can ever be maintained. Such natural rules...from their being extremely simple, intelligible and efficacious, can be easily applied by the draftsman (sic).... To ascertain these natural rules, it is necessary first to determine what are essentially the elements of a legislative expression. ${ }^{37}$

Coode was calling, in effect, for a logical syntax for legal drafting: rules reflecting the essence of the drafter's task, which, if followed, would avoid nonsensical constructions.

Surely one reason legal drafters so often fall short of clarity is that they are pushing imperative language far beyond its everyday use. And surely Coode was correct: before legal drafting can be improved, its essential nature must be analyzed and understood. That is a big task, hardly begun. 